University of Nebraska - Lincoln

DigitalCommons@University of Nebraska - Lincoln

\title{
Does Bisphenol A Induce Superfeminization in Marisa cornuarietis? Part I: Intra- and Inter-Laboratory Variability in Test Endpoints
}

\author{
Valery E. Forbes \\ University of Nebraska-Lincoln, veforbes@umn.edu \\ Henriette Selck \\ Roskilde University, hse@virgil.ruc.dk \\ Annemette Palmqvist \\ Roskilde University, Denmark \\ John Aufderheide \\ ABC Laboratories, Inc., Columbia, Missouri \\ Ryan Warbritton \\ ABC Laboratories, Inc., Columbia, Missouri
}

See next page for additional authors

Follow this and additional works at: https://digitalcommons.unl.edu/biosciforbes

Part of the Pharmacology, Toxicology and Environmental Health Commons

Forbes, Valery E.; Selck, Henriette; Palmqvist, Annemette; Aufderheide, John; Warbritton, Ryan; Pounds, Nadine; Thompson, Roy; and Caspers, Norbert, "Does Bisphenol A Induce Superfeminization in Marisa cornuarietis? Part I: Intra- and Inter-Laboratory Variability in Test Endpoints" (2007). Valery Forbes Publications. 25.

https://digitalcommons.unl.edu/biosciforbes/25

This Article is brought to you for free and open access by the Papers in the Biological Sciences at DigitalCommons@University of Nebraska - Lincoln. It has been accepted for inclusion in Valery Forbes Publications by an authorized administrator of DigitalCommons@University of Nebraska - Lincoln. 


\section{Authors}

Valery E. Forbes, Henriette Selck, Annemette Palmqvist, John Aufderheide, Ryan Warbritton, Nadine Pounds, Roy Thompson, and Norbert Caspers 
Published in Ecotoxicology and Environmental Safety 66 (2007), pp. 309-318; DOI: 10.1016/j.ecoenv.2006.10.014.

Copyright (C) 2007 Elsevier Inc. Used by permission.

Submitted July 10, 2006; revised October 20, 2006; accepted October 25, 2006; published online December 8, 2006.

\title{
Does Bisphenol A Induce Superfeminization in Marisa cornuarietis? Part I: Intra- and Inter-Laboratory Variability in Test Endpoints
}

\author{
Valery E. Forbes, ${ }^{1}$ Henriette Selck, ${ }^{1}$ Annemette Palmqvist, ${ }^{1}$ John Aufderheide, ${ }^{2}$ Ryan Warbritton, ${ }^{2}$ \\ Nadine Pounds, ${ }^{3}$ Roy Thompson, ${ }^{3}$ Nelly van der Hoeven, ${ }^{4}$ Norbert Caspers ${ }^{5}$ \\ 1. Department of Environmental, Social and Spatial Change, Roskilde University, Roskilde, Denmark \\ (Corresponding author, Forbes: vforbes3@unl.edu; affiliation 2010- University of Nebraska-Lincoln, \\ Lincoln, Nebraska, USA) \\ 2. ABC Laboratories, Inc., Columbia, Missouri, USA \\ 3. Brixham Environmental Laboratory, AstraZeneca UK Limited, Freshwater Quarry, Devon, UK \\ 4. Ecostat, Leiden, The Netherlands \\ 5. Bayer Industry Services, Leverkusen, Germany
}

\begin{abstract}
It has been claimed that bisphenol A (BPA) induces superfeminization in the freshwater gastropod, Marisa cornuarietis. To explore the reproducibility of prior work, here we present results from a three-laboratory study, the objectives of which were to determine the mean and variability in test endpoints (i.e., adult fecundity, egg hatchability, and juvenile growth) under baseline conditions and to identify the sources of variability. A major source of variability for all of the measured endpoints was due to differences within and among individuals. With few exceptions, variability among laboratories and among replicate tanks within laboratories contributed little to the observed variability in endpoints. The results highlight the importance of obtaining basic knowledge of husbandry requirements and baseline information on life-history traits of potential test species prior to designing toxicity test protocols. Understanding of the levels and sources of endpoint variability is essential so that statistically robust and ecologically relevant tests of chemicals can be conducted.
\end{abstract}

Keywords: endocrine disruption, gastropod, reproduction, risk assessment, test design

\section{Introduction}

Bisphenol A (BPA; 4,4-isopropylidene diphenol) is a chemical intermediate used primarily in the production of epoxy resins and polycarbonate products (Staples et al., 1998). The extent to which low doses of bisphenol A cause reproductive and developmental effects in humans has been extensively reviewed (Vom Saal and Hughes, 2005; Goodman et al., 2006). The environmental toxicology of BPA has also been the subject of much investigation, and the compound is known to be weakly estrogenic from studies conducted with a number of aquatic vertebrate and invertebrate species (EC, 2003; Staples et al., 2002). Several recent papers by Oehlmann and colleagues have claimed that BPA induces superfeminization in the gastropod Marisa cornuarietis. These effects include for- mation of additional female organs, enlarged accessory sex glands, gross malformations of the pallial oviduct, and a stimulation of egg and egg mass production resulting in increased female mortality (Oehlmann et al., 2000, 2006a; Schulte-Oehlmann et al., 2001). If these claims are valid, they can have an important influence on the risk assessment for this chemical, since, on the basis of the above results, $M$. cornuarietis would seem to be more sensitive than all other aquatic invertebrates so far tested.

$M$. cornuarietis is a common species in the tropics and subtropics that has been extensively studied for its potential as a biological control agent (WHO, 1982). Although much has been published on its biology and ecology, there are a number of problems with using $M$. cornuarietis in ecotoxicological testing that need to be addressed in order to confirm whether BPA has effects on this spe- 
cies at environmentally relevant concentrations. These problems include a lack of basic knowledge of the influence of husbandry conditions on the performance of $M$. cornuarietis and the variability of its life-history traits under laboratory conditions, no replication of BPA treatments in most of the published experiments with this species (i.e., Schulte-Oehlmann et al., 2001; Oehlmann et al., 2000, 2006a, Exposure Series I), associated with the application of inappropriate statistical techniques, that make claims of statistical significance highly questionable (Dietrich et al., 2006, cf., Oehlmann et al., 2006b).

With regard to life-history traits, knowledge of the degree of variability in laboratory baseline (control) values for traits used as ecotoxicological test endpoints is critical for assessing whether cultures are of suitable condition for use in testing. Moreover knowledge of laboratory baseline values is a requirement to design tests with sufficient statistical power to allow detection of effects of chemical (or other) treatments. Although Oehlmann et al. (2006a) reported to observe seasonality in reproductive output of $M$. cornuarietis when snails are grown under constant culture conditions, an explanation for this apparent seasonality has not been forthcoming, and we have found no other reports of reproductive seasonality under controlled laboratory conditions in this species. Furthermore, Oehlmann et al. (2006a) suggest that enhancements of reproductive output (e.g., induced by BPA) may only be detectable in the non-reproductive period.

In light of the deficiencies in baseline knowledge about $M$. cornuarietis, the experiments presented here are part of an extensive study that aims to obtain basic understanding of the biology of $M$. cornuarietis, focusing on those aspects that are of high relevance to ecotoxicological testing, and to use these results to develop a robust experimental design with appropriate statistical power to detect potential effects of BPA on all phases of the life cycle of this species (juvenile and adult survival, juvenile growth, adult reproduction, egg hatchability and development).

In Part I of this two-part series we present results from a three-laboratory study, the objective of which was to quantify the mean and variability in key test endpoints under baseline (unexposed) conditions, and to identify the sources of this variability. In each laboratory, three types of experiments were performed (Adult Fecundity Trials, Egg Hatchability Trials, and Juvenile Growth Trials) so that baseline values for key endpoints from all phases of the life cycle of $M$. cornuarietis could be determined. Part II (Forbes et al., in press) shall provide preliminary toxicity test results that will be employed in a statistical power analysis and used to optimize the design of future toxicity tests.

\section{Materials and methods}

\subsection{Culture establishment and experimental conditions}

Wild specimens of M. cornuarietis were collected from Lake Guajataca, Puerto Rico (see Aufderheide et al. (2006), for site details and collection methods). Between 150 and 200 snails (referred to as $F_{0}$ snails) were sent to the participating laboratories, ABC Laboratories, USA (ABC), Brixham Environmental Laboratory, UK (BEL), and Roskilde University, DK (RUC), by overnight express mail and established as stock cultures. Both culture and subsequent test conditions were established following consultation with experts that have worked extensively with $M$. cornuarietis and were kept as uniform as possible among the participating laboratories. Cultures were maintained at a temperature of $25( \pm 1)^{\circ} \mathrm{C}$, with a photoperiod of $12 \mathrm{~h} \mathrm{~L}: 12$ $h$ D. Snails were fed fresh lettuce (Lactuca sativa) and commercial algal wafers (supplied by Hikari, USA, http://www.hikariusa.com/algae_wafers.htm and available from a local aquarium supplier) three times weekly. Water quality parameters were measured regularly and maintained within agreed limits: $\mathrm{pH}$ : 7.3-8.1; calcium concentration: $50-125 \mathrm{mg} / \mathrm{L}$; dissolved oxygen: $>60 \%$ saturation; ammonium: $<0.2 \mathrm{mg} / \mathrm{L}$.

While all three laboratories conducted the experiments at a temperature of $25( \pm 1)^{\circ} \mathrm{C}, \mathrm{ABC}$ also conducted a parallel set of experiments at $22^{\circ} \mathrm{C}$ in order to examine temperature effects on test endpoints.

The main difference among participating laboratories was that $\mathrm{ABC}$ and BEL used flow-through aquarium systems (with a water replacement rate during the experiments of 10 volume renewals per day) whereas RUC used a semi-static system with water renewed every 2-4 weeks depending on water quality measures. The semi-static systems were fitted with an external Eheim Model 2231 three-stage canister filter, a heater and an air stone.

\subsection{Adult fecundity trials}

Three replicate glass aquaria $(25 \mathrm{~L}$ water volume for flow-through systems and $50 \mathrm{~L}$ water volume for semi-static systems) were each divided into 10 chambers by perforated glass partitions, resulting in a snail density of 0.8 and 0.4 snails/L for the flow-through and semistatic systems, respectively. Snails were sexed on the basis of differences in head/foot coloration (Aufderheide et al., 2006), and one male and one female snail were added to each chamber. The trial was initiated with snails that were produced in the laboratory (at least $F_{1}$ generation), that were of known age (approximately 4 months) and size (29-40 mm shell diameter for males and $30-40 \mathrm{~mm}$ for females). Snails in each chamber were fed fresh lettuce and algal wafers three times per week. At each feeding, the snails received approximately $2 \mathrm{~g}$ of lettuce and $1 / 2$ of an algal wafer. Any uneaten food was removed on the next feeding occasion. Chambers were checked three times weekly for the presence of eggs. Both numbers of egg masses and numbers of eggs per egg mass were recorded. After a 1-month acclimation period (during which any pairs that did not produce at least one egg mass were replaced), egg production was measured during a period of at least 6 months in all laboratories. At RUC this trial was extended for an additional 7 months for the specific purpose of investigating seasonal changes in reproductive output. Female reproductive performance is expressed in terms of number of eggs per female per month (= number of eggs per egg mass $\times$ number of egg masses per female per month).

To quantify the relative importance of intra- and inter-laboratory variability in egg production, nested analysis of variance (ANOVA) was used (Sokal and Rohlf, 1995) in which replicate aquaria were nested within laboratory, and the dependent variable was eggs/female/month (average for each female over the entire trial; $\mathrm{n}=10$ per replicate aquarium). The effect of temperature on reproductive output was tested by ANOVA (for ABC laboratory) using the average eggs/ female/month per replicate as the dependent variable $(n=3$ per temperature treatment).

\subsection{Egg hatchability trials}

Hatchability trials were conducted twice, and were initiated approximately 1 and 4 months after initiation of the adult fecundity trials. Trials were initiated by the selection of five females from each replicate aquarium. The selection process was conducted when at least 5 females in the same aquarium over a short time period (ideally within 
$24 \mathrm{~h})$ produced an egg mass. If more than five females produced an egg mass during the time period, the five females were selected randomly. For both hatchability trials, five consecutive egg masses were collected from each of the selected females, resulting in 25 egg masses per replicate and 75 egg masses in total. The numbers of eggs per egg mass were counted, and the egg masses were placed separately in hatching baskets. A hatching basket consisted of a glass Petri-dish to which a cylinder of nylon mesh (355 mm mesh size) was attached with silicone. The baskets were submerged in hatching aquaria and were checked daily. Time to first hatch (i.e. number of days until the first egg hatched), and time to $50 \%$ hatch (i.e. number of days until $50 \%$ of the eggs had hatched) were recorded. The egg masses were followed for 2 weeks subsequent to first hatch, and any eggs that had not hatched by this time were defined as non-viable (this definition was validated by unpublished pilot studies). Percent hatchability was calculated as the number of eggs hatched by the end of the 2-week hatching period, divided by egg mass size, multiplied by 100 .

Two-level nested ANOVAs were used to quantify the relative importance of intra- and inter-laboratory variability in time to first- and $50 \%$-hatch and to partition the total variance in these traits into variance attributed to replicate aquaria and that due to differences among pairs of snails (within replicate aquaria). Since percent hatch data were not normally distributed (and could not be transformed so as to fit a normal distribution), differences among laboratories in this trait were analyzed by nonparametric Kruskal-Wallis tests for each trial separately (using means for each replicate). Kruskal-Wallis tests (of means per replicate) were also used to test for differences in percent hatch between trials for each laboratory separately, whereas Student's $t$-tests were used to test for differences between trials in time to firstand $50 \%$-hatch (using means for each replicate), for each laboratory separately. Effects of temperature on hatchability traits were tested by Student's $t$-tests (time to first-and $50 \%$ hatch) and the Kruskal-Wallis test (percent hatch) using means for each replicate (trials pooled).

\subsection{Juvenile growth trials}

The juvenile growth trial was a continuation of the first hatchability trial. The growth trial was initiated when the first of the 5 females used for the hatchability trial had produced her fifth egg mass. On this date egg masses were collected from the same five females used for the hatchability trial and transferred to hatching baskets as above. Following hatching of the egg masses, 20 juvenile snails were randomly selected from each mass (to provide a uniform snail density in each basket) and allowed to grow up to a size that would permit handling. Approximately 1 month post-hatch, five juvenile snails per female were selected randomly from the original 20, blotted dry, and individually identified by marking the shell with a fine-point permanent marker. Unpublished pilot trials showed that this procedure did not adversely affect snail growth or survival. Subsequently, the 25 snails (five from each of the five females) were placed in an aquarium of the same dimensions as used in the adult fecundity trial but without the partitions. The 10-15 remaining snails from each egg mass were marked and kept to replace animals from the experimental aquaria that died or were dying due to handling injuries. Replacements were only performed as needed during the first 2 weeks of the trial, after which no further replacements were made. Snail shell diameter was measured weekly to the nearest $0.1 \mathrm{~mm}$ with hand-held calipers (Aufderheide et al., 2006) or an image analysis system (Selck et al., 2006) and wet weights were measured to the nearest $0.1 \mathrm{mg}$ on a laboratory balance after gently blotting excess water from the shell.

Juvenile growth rates were calculated by fitting a third degree polynomial to the data set for each individual, and calculating the growth rate at 60 days post-hatch (dph) from the equations. Only individuals with at least four data points were used to estimate the parameters of the polynomial function. Growth rates as well as shell diameters and wet weights at $60 \mathrm{dph}$ were compared by nested ANOVA (with replicate aquaria and mothers nested within laboratories). The effect of temperature on growth was tested by ANOVA on growth rate, shell diameter and wet weight at $60 \mathrm{dph}$ at 22 and $25^{\circ} \mathrm{C}$ (ABC data).

\section{Results}

\subsection{Adult fecundity trials}

Egg production rates for the three laboratories are shown in Figure 1 . At $25^{\circ} \mathrm{C}$ there were no significant differences among laboratories in the average number of eggs/female/month $(P=0.19)$ or among replicate aquaria within laboratories $(P=0.32)$. Only $1.9 \%$ of the total variance in egg production was due to differences among replicate aquaria within laboratories, $4.4 \%$ was due to differences among laboratories, whereas $93.7 \%$ of the total variance in egg production could be explained by differences among pairs of snails within replicate aquaria.

Egg production rates appeared to decline with time in all three laboratories. Monthly per female egg production rates declined from an average of 619 in the first month of the trial to 310 in the seventh month at $\mathrm{ABC}$, from 580 to 338 at BEL, and from 736 to 187 at RUC. For the trials at $A B C$ and BEL it is not possible to determine whether this was a result of seasonal changes in reproduction or was due to snail age. The extended trial at RUC indicated that egg production rates declined during around the first 6 months of the trial and thereafter remained relatively constant (Figure 2). Comparison of egg production rates at the start of the trial (month 1 of the trial and month 7 of the year) with egg production rates exactly 1 year later (triangles in Figure 2a, b) clearly indicate that reproductive output did not return to similar levels and that therefore the observed changes in reproductive output were not part of a seasonal cycle.

Comparison of the parallel trials at $A B C$ showed that adult snails had a significantly lower reproductive output at $22^{\circ} \mathrm{C}$ compared to $25^{\circ} \mathrm{C}(P=0.02)$. Average eggs/ female/month was $440(\mathrm{SD}=28.8 ; n=3)$ at the higher temperature and $284(\mathrm{SD}=59.2 ; n=3)$ at the lower temperature. Not only was reproductive output lower at the lower temperature, but between-replicate variability was also higher $\left(\mathrm{CV}=6.6 \%\right.$ at $25^{\circ} \mathrm{C}$ and $21.0 \%$ at $\left.22^{\circ} \mathrm{C}\right)$.

\subsection{Egg hatchability trials}

The number of days to first-and $50 \%$ hatch in each of two trials and three laboratories is shown in Figure 3. In the first trial there was no difference among laboratories $(P=0.94)$ or replicate aquaria $(P=0.36)$ in time to first hatch, though there were significant differences among females within replicate aquaria $(P=0.03)$. Approximately $0 \%$ of the variance in time to first hatch was due to laboratories, $0.7 \%$ was due to replicate aquaria, $9.9 \%$ was due to females within replicates, and $89.4 \%$ was due to variability among egg masses within females. Likewise in trial 1, there was no difference among laboratories in time to $50 \%$ hatch $(P=0.34)$, though there were significant differences among replicate aquaria within laboratories $(P=0.02)$ and among females within replicate aquaria $(P$ $<0.001)$. Laboratories contributed $1.8 \%$ to the total vari- 

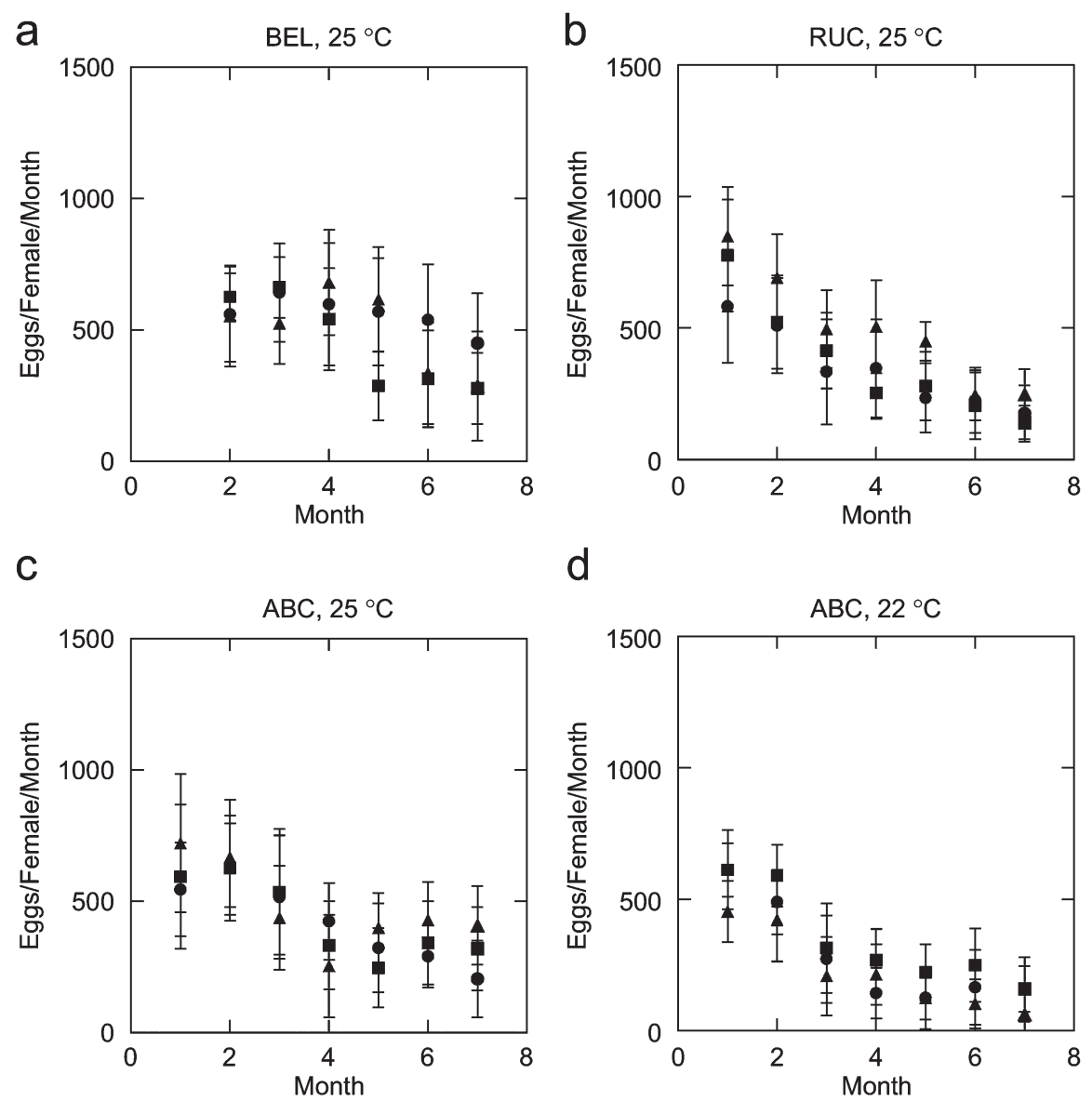

d

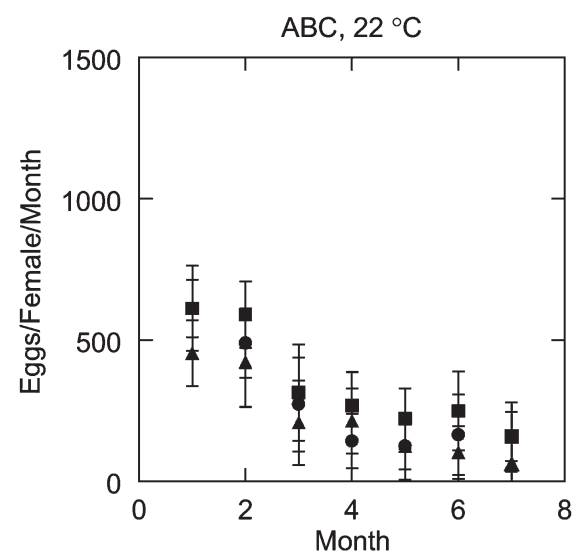

Figure 1. Average eggs/female/month produced during the adult fecundity trials in the three laboratories. $(\mathrm{A}) \mathrm{BEL}, 25^{\circ} \mathrm{C}$; $(\mathrm{B})$ RUC, $25^{\circ} \mathrm{C}$; (C) ABC, $25^{\circ} \mathrm{C}$; (D) ABC, $22^{\circ} \mathrm{C}$. Different symbols represent replicate aquaria. Error bars indicate $95 \%$ confidence intervals around means.

ance in time to $50 \%$ hatch, replicates contributed $11.5 \%$, females contributed $16.7 \%$, whereas $70 \%$ of the total variance in this trait was due to variability among egg masses within females.

In the second trial, there were significant differences among laboratories in time to first hatch $(P<0.001)$, but no differences among replicate aquaria within laboratories $(P=0.15)$ or among females within replicates $(P=$ 0.18 ). Laboratories contributed $52.9 \%$ to the total variance in time to first hatch, replicates contributed $1.5 \%$, females within replicates contributed $2.1 \%$, and within-female variability (i.e., differences among egg masses produced by the same female) contributed $43.6 \%$ to the total variance in this trait. Likewise in trial 2, there was a significant difference among laboratories in time to $50 \%$ hatch $(P=0.01)$, no difference among replicate aquaria within laboratories $(P=0.51)$, and a marginal difference among females within replicates $(P=0.08)$. Laboratories contributed $13.9 \%$ to the total variance in time to $50 \%$ hatch, replicates contributed $0 \%$, females within replicates contributed $6.5 \%$ and within-female variability explained $79.6 \%$ of the total variance in this trait.

There was no difference among laboratories in percent hatch in the first trial $(P=0.11)$, but a marginally signifi- cant difference in the second trial $(P=0.05)$ with a lower hatchability at BEL compared to the other two laboratories (Table 1). Comparisons between trials for each laboratory separately found no significant difference in percent hatch for $\operatorname{ABC}(P=0.28)$ or RUC $(P=0.51)$, but a significant difference at BEL $(P=0.05)$ with a lower percent hatch in the second trial. It took longer to reach first hatch in the second trial than the first at $\mathrm{ABC}(P=0.01$; average per replicate aquarium: 10.5 days vs. 11.7 days). The reverse was the case for BEL $(P<0.001$; average per replicate aquarium: 10.6 days vs. 9.1 days), and there was no difference in time to first hatch between trials at RUC ( $P=0.70$; average per replicate aquarium: 10.6 days vs. 10.7 days). Time to $50 \%$ hatch was also longer in the second compared to the first trial at $\mathrm{ABC}(P=0.002$; average per replicate aquarium: 11.6 vs. 12.7 days), but there was no difference between trials in time to median hatch at BEL ( $P=0.20$; average per replicate aquarium: $11.6 \mathrm{vs}$. 11.7 days) or RUC ( $P=0.31$; average per replicate aquarium: 12.1 vs. 11.5 days).

Percent hatch was lower at $22^{\circ} \mathrm{C}$ than at $25^{\circ} \mathrm{C}(P=0.05)$ (Table 1), and it took significantly longer for eggs to reach first- $(P=0.001 ; 16.9$ vs. 11.1 days $)$ and $50 \%$ hatch $(P=0.001$; 19.1 vs. 12.1 days) at the lower temperature (Figure 4 ). 

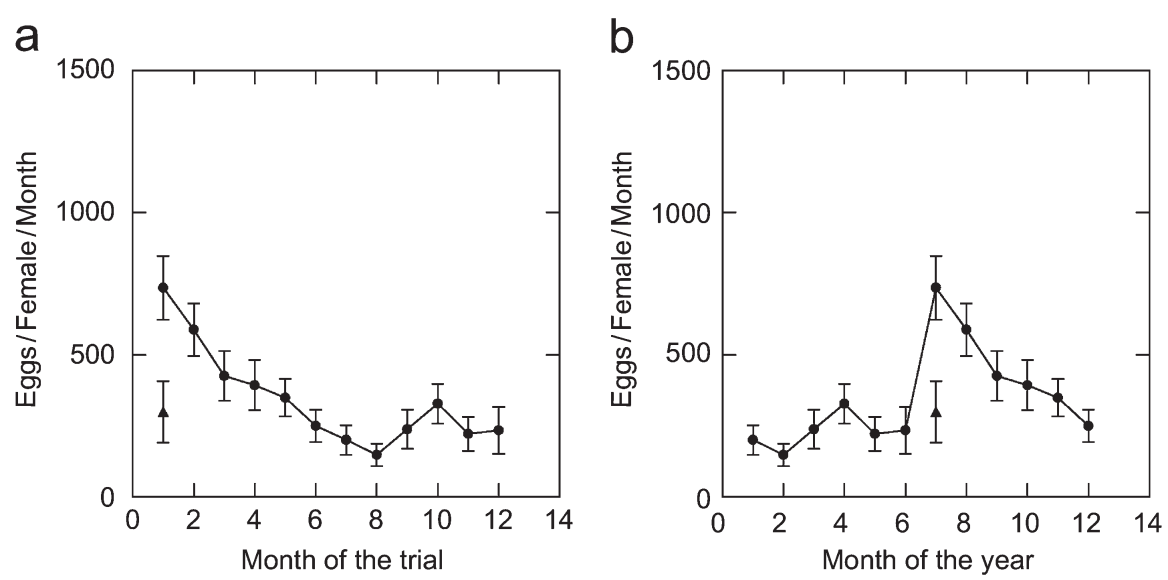

Figure 2. Average eggs/female/month (all replicates pooled) plotted against (a) month from the start of the trial (month $1=$ July) and (b) month of the year (month 1 = January) for the extended adult fecundity trial conducted at RUC. Error bars indicate $95 \%$ confidence intervals around means.
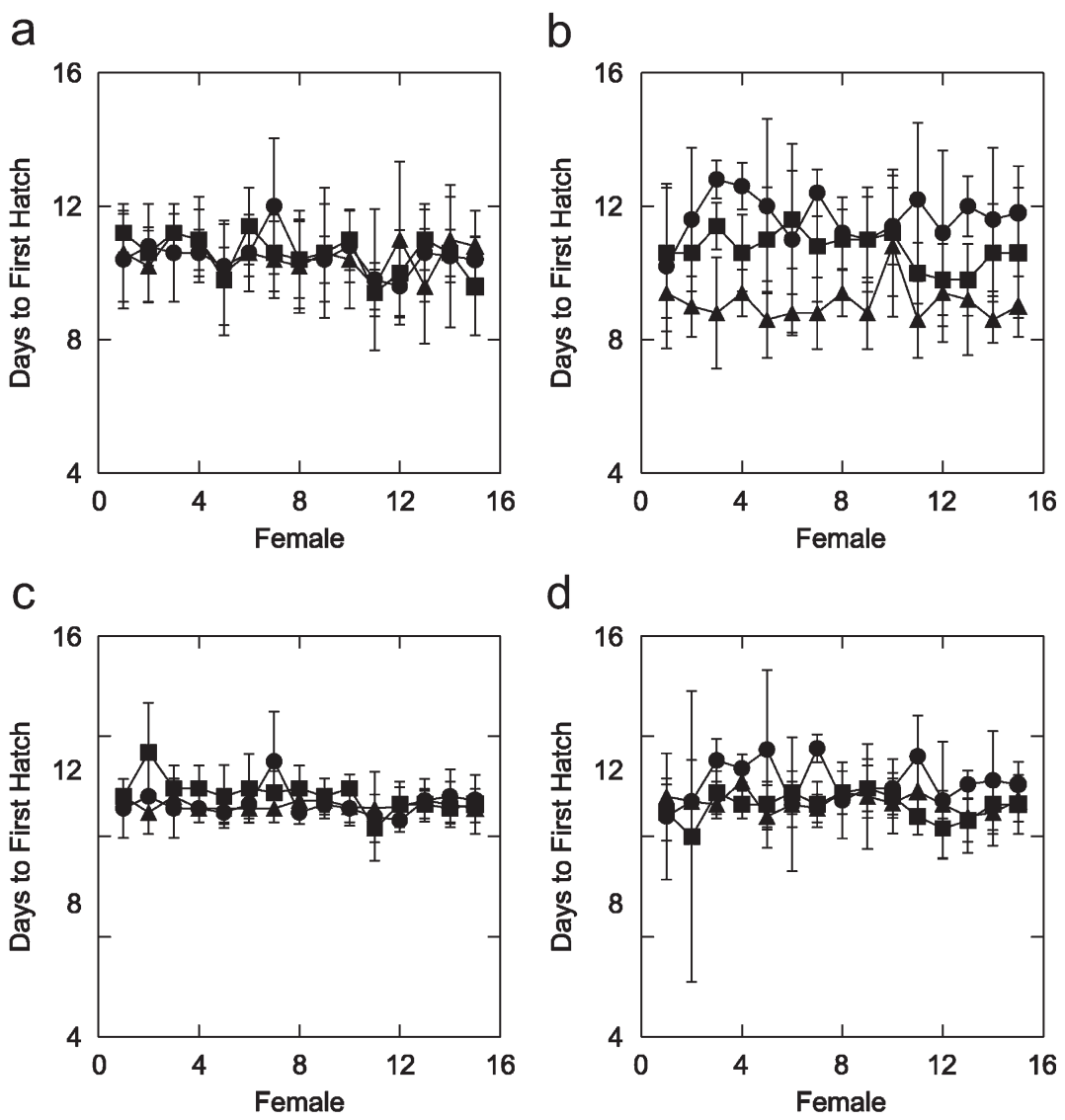

Figure 3. Average days to first- (top row) and 50\% (bottom row) hatch for egg masses produced during the egg hatchability trials at $25^{\circ} \mathrm{C}$. First trial $=\mathrm{a}, \mathrm{c}$; second trial $=\mathrm{b}$, d. Circles $=\mathrm{ABC}$; triangles $=\mathrm{BEL}$; squares $=$ RUC. Error bars represent $95 \%$ confidence limits around means.

\subsection{Juvenile growth trials}

Snails increased rapidly in size in all laboratories and replicates (Figure 5). Comparisons of shell diameters and wet weights at $60 \mathrm{dph}\left(\right.$ and $25^{\circ} \mathrm{C}$ ) showed that there was a significant effect of laboratory $(P<0.001)$, of replicates within laboratories (shell diam: $P=0.02$; wet wt: $P=0.001$ ), and of mothers (shell diam: $P<0.001$; wet wt:
$P=0.002)$. Average shell diameters at $60 \mathrm{dph}$ were 23.4 $\mathrm{mm}(\mathrm{SD}=1.97)$ at $\mathrm{ABC}, 14.4 \mathrm{~mm}(\mathrm{SD}=1.31)$ at $\mathrm{BEL}$, and $13.6 \mathrm{~mm}(\mathrm{SD}=1.39)$ at RUC, whereas average wet weights were $2.8 \mathrm{~g}(\mathrm{SD}=0.64)$ at $\mathrm{ABC}, 0.8 \mathrm{~g}(\mathrm{SD}=0.21)$ at $\mathrm{BEL}$, and $0.7 \mathrm{~g}(\mathrm{SD}=0.19)$ at RUC.

The growth rates at $60 \mathrm{dph}$ are shown in Table 2. For wet weight growth rate at $25^{\circ} \mathrm{C}, 84 \%$ of the total variance in this endpoint was due to the laboratory, $3.1 \%$ was due 

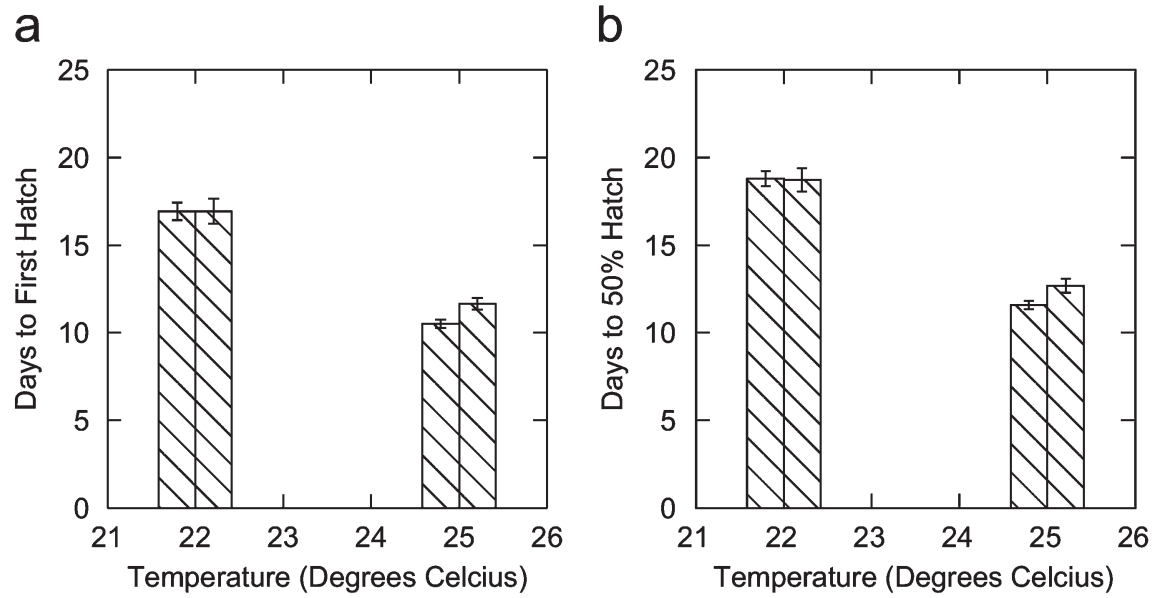

Figure 4. Effect of temperature on time to first (a) and 50\% (b) hatch. Error bars represent $95 \%$ confidence limits around means. Bars on left of each pair indicate first trial; bars on the right of each pair indicate second trial. Data from ABC Laboratory.

to the effect of the mother and $12.8 \%$ was due to inter-individual variance. For shell diameter growth rate at $25^{\circ} \mathrm{C}$, $33 \%$ of the total variance in this endpoint was due to the laboratory, $12.6 \%$ was due to the replicate, $21.61 \%$ was due to the effect of the mother and $32.8 \%$ was due to inter-individual variance.

Comparing the two growth trials at $\mathrm{ABC}$ Laboratory showed that snail growth rates were markedly slower at $22^{\circ} \mathrm{C}$ compared to $25^{\circ} \mathrm{C}$. Snails reached a shell diameter and wet weight at $60 \mathrm{dph}$ of only $16.4 \mathrm{~mm}$ and $1.06 \mathrm{~g}$, respectively, at $22^{\circ} \mathrm{C}$ compared to $23.4 \mathrm{~mm}$ and $2.84 \mathrm{~g}$ at $25^{\circ} \mathrm{C}$ (Table 2). Comparing the observations at $22^{\circ} \mathrm{C}$ versus $25^{\circ} \mathrm{C}$ showed that $84 \%$ of the variance in wet weight growth rate was due to temperature, $0.4 \%$ was due to replicate, $3.2 \%$ was due to the effect of the mother and $12.3 \%$ was due to inter-individual variance. For shell diameter growth rate, $65 \%$ of the variance was due to temperature, $14.6 \%$ was due to replicate, $2.9 \%$ was due to the effect of the mother and $17.2 \%$ was due to inter-individual variance. It should be noted that the inter-replicate variance in the $\mathrm{ABC}$ laboratories was relatively large compared to

Table 1. Egg hatchability trials

\begin{tabular}{clllll}
\hline Trial Replicate & $\mathrm{ABC}, 22^{\circ} \mathrm{C}$ & $\mathrm{ABC}, 25^{\circ} \mathrm{C}$ & $\mathrm{BEL}, 25^{\circ} \mathrm{C}$ & $\mathrm{RUC}, 25^{\circ} \mathrm{C}$ \\
\hline 1 & 1 & 98.0 & 100 & 94.3 & 93.2 \\
& \multirow{2}{*}{2} & $(22,88-100)$ & $(25,96-100)$ & $(25,80-107)$ & $(25,56-108)$ \\
& 97.0 & 100 & 94.8 & 96.3 \\
& 3 & $(24,38-100)$ & $(25,10-100)$ & $(25,38-133)$ & $(25,87-101)$ \\
& & 96.5 & 100 & 91.5 & 95.8 \\
2 & \multirow{2}{*}{1} & $(22,79-100)$ & $(24,98-100)$ & $(25,28-103)$ & $(25,79-110)$ \\
& & 97.0 & 100 & 76.8 & 92.6 \\
& 2 & $(12,17-100)$ & $(22,54-100)$ & $(25,37-101)$ & $(25,44-104)$ \\
& & $(15,9-100)$ & $(25,87-100)$ & $(25,2-114)$ & $(25,85-101)$ \\
& 3 & 95.0 & 98.0 & 81.6 & 93.9 \\
& $(19,71-100)$ & $(25,76-100)$ & $(25,26-112)$ & $(25,83-105)$ \\
\hline
\end{tabular}

Values shown are medians ( $n$, range) of each replicate aquarium for percent hatch. Values greater than $100 \%$ occurred in some egg masses as a result of eggs containing multiple embryos. that at RUC and BEL leading to a larger estimate of the effect of replicate in the between temperature comparison than in the among-laboratory comparison.

\section{Discussion}

In terms of husbandry requirements, relatively little has been published about effects of photoperiod, temperature, food and water quality, and snail density on the performance of $M$. cornuarietis under controlled laboratory conditions. Aufderheide et al. (2006) showed that whereas changing photoperiod from 12 to $16 \mathrm{~h}$ of light per day had no effect on adult fecundity or egg hatchability and little effect on juvenile growth and development of $M$. cornuarietis, varying temperature in the range 22$28^{\circ} \mathrm{C}$ had significant effects on snail growth and development, with poorer performance at the lower temperature. This same study also showed that maintaining snails at a density above 0.8 snails/L, even under flow-through conditions, has a negative impact on snail performance. Selck et al. (2006) demonstrated the importance of maintaining consistent high availability and quality of food to ensure adequate growth and survival of juvenile $M$. cornuarietis. On the basis of these and other previously published studies, we aimed to culture snails under uniform and favorable conditions to gather baseline information on key life-history traits and to quantify inter- and intra-laboratory sources of variability in these traits. The results show that a major source of variability for all of the measured traits is due to variability within and among laboratories and among replicate aquaria within laboratories contributed relatively little to the observed variability in measured traits.

Given the large contribution of intra- and inter-snail differences to test endpoint variability, the designs used in the present study, which allow individual identification of adult pairs, egg masses and juveniles, offer a num- 
a

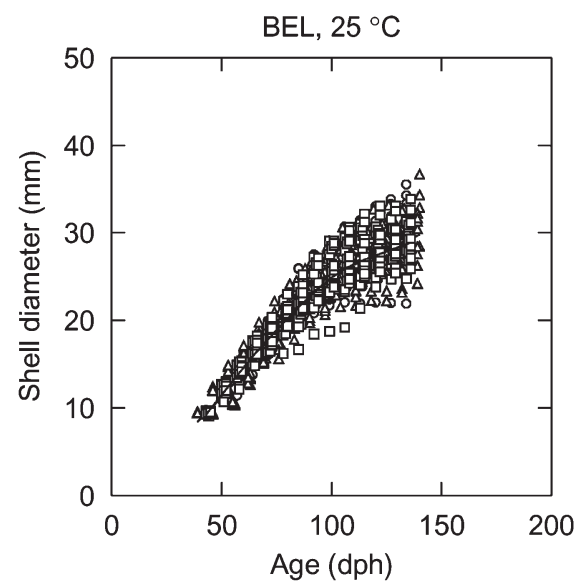

C

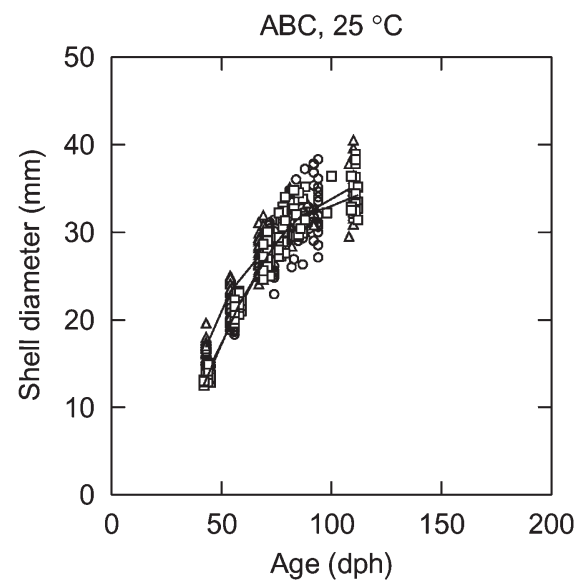

b

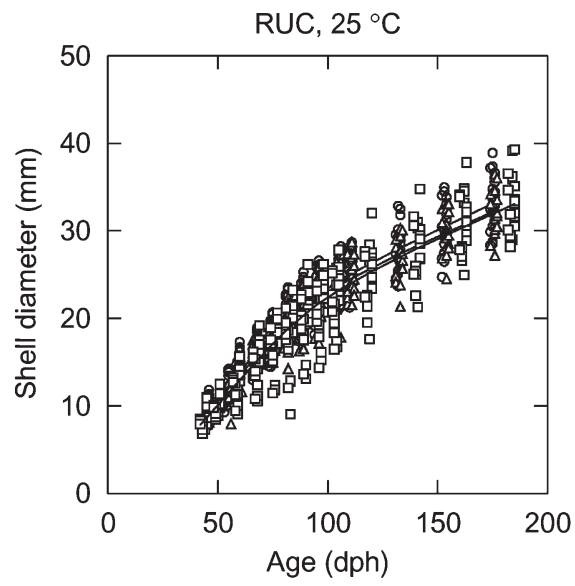

d

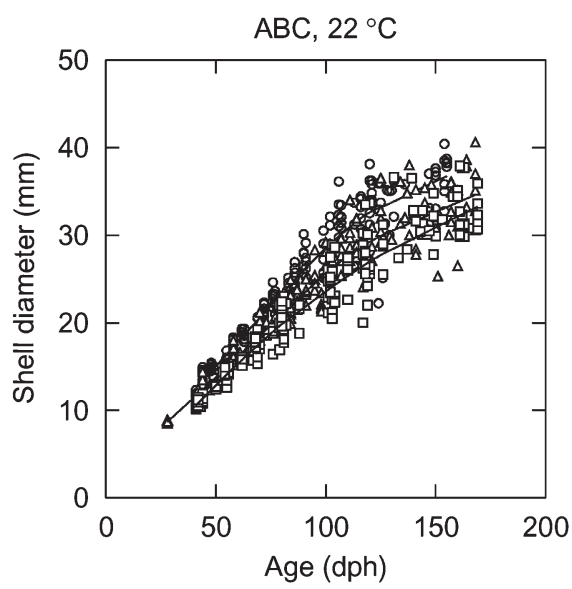

Figure 5. Relationship between snail shell diameter and age (days post-hatch) for juvenile growth trials. Different symbols indicate replicate aquaria. Curves represent locally weighted scatterplot smooths fitted to the data (A) $\mathrm{BEL}, 25^{\circ} \mathrm{C}$; $(\mathrm{B}) \mathrm{RUC}, 25^{\circ} \mathrm{C}$; $(\mathrm{C})$ $\mathrm{ABC}, 25^{\circ} \mathrm{C}$; (D) $\mathrm{ABC}, 22^{\circ} \mathrm{C}$.

ber of advantages over group housing (as used by Oehlmann et al., 2000, 2006a; Schulte-Oehlmann et al., 2001). First, it can be determined whether applied treatments affect all individuals similarly, or only a sensitive subgroup of the population. Second, unintentional biases in the allocation of snails to treatment groups can be detected. Similarly, outliers (e.g., unusually high- or low reproducers) can be identified and omitted from analyses if necessary. Third, for the same number of replicates (i.e., aquaria) per treatment, and minimal additional effort, much more information on the biological responses of interest, and their variability, can be obtained. Fourth, the design avoids potential problems of competition among snails reared in large groups which could lead to differences in food availability per snail if some individuals are better at competing for food than others.

Adult M. cornuarietis used for the experiments reported here showed generally higher reproductive outputs than those reported by Oehlmann et al. (2000), Schulte-Oehlmann et al. (2001), and Oehlmann et al. (2006a), but which are consistent with other published reports (Haridi et al.,
Table 2. Juvenile growth trials

\begin{tabular}{llcccc}
\hline Temperature & & $\begin{array}{c}22{ }^{\circ} \mathrm{C} \\
\mathrm{ABC}\end{array}$ & $\begin{array}{c}25^{\circ} \mathrm{C} \\
\mathrm{ABC}\end{array}$ & $\begin{array}{c}25^{\circ} \mathrm{C} \\
\mathrm{RUC}\end{array}$ & $\begin{array}{c}25^{\circ} \mathrm{C} \\
\mathrm{BEL}\end{array}$ \\
\hline Growth rate & Mean & 0.047 & 0.145 & 0.038 & 0.050 \\
of wet-weight & $\mathrm{SD}$ & 0.013 & 0.041 & 0.013 & 0.012 \\
(g/day) & $\mathrm{CV}$ & 27.1 & 28.2 & 34.7 & 24.4 \\
Growth rate & Mean & 0.264 & 0.429 & 0.304 & 0.339 \\
of diameter & $\mathrm{SD}$ & 0.047 & 0.100 & 0.066 & 0.072 \\
(mm/day) & $\mathrm{CV}$ & 17.6 & 23.2 & 21.9 & 21.2 \\
Wet weight (g) & Mean & 1.06 & 2.84 & 0.69 & 0.77 \\
& $\mathrm{SD}$ & 0.23 & 0.64 & 0.19 & 0.21 \\
& $\mathrm{CV}$ & 22.0 & 22.7 & 27.2 & 27.1 \\
Diameter (mm) & $\mathrm{Mean}$ & 16.4 & 23.4 & 13.6 & 14.4 \\
& $\mathrm{SD}$ & 1.4 & 2.0 & 1.4 & 1.3 \\
& $\mathrm{CV}$ & 8.3 & 8.4 & 10.2 & 9.0 \\
\hline
\end{tabular}

Estimates of the growth rates in wet weight (g/day) and in diameter (mm/day) at 60 days post-hatch $(\mathrm{dph})$ and of the wet weight and diameter at $60 \mathrm{dph}$ at $25^{\circ} \mathrm{C}$ for all three laboratories and at $22^{\circ} \mathrm{C}$ for $\mathrm{ABC}$ only. 
1985; Cowie, 2002). From Figure 2 in Oehlmann et al. (2006a) monthly per female reproductive output (in snails not exposed to BPA) can be estimated to be about 105 and 140 eggs/female/month at 20 and $27^{\circ} \mathrm{C}$, respectively. Haridi et al. (1985) reported daily egg production rates in laboratory populations of M. cornuarietis (derived from three sites in Puerto Rico (including Lake Guajataca)) of up to 20 eggs per adult snail (or 600 eggs/snail/month) at temperatures between 28 and $30^{\circ} \mathrm{C}$. It has been reported that in nature one snail can produce an average of 4375 (maximum observed 8680) eggs per year (Mochida 1988a, 1991 cited in Cowie, 2002), which is equivalent to an average of 365 (and maximum of 723) eggs/month. In the present study, mean (of three replicates) egg production rates were: $440( \pm 28.9)$ eggs/female/month at $\mathrm{ABC}, 504$ $( \pm 54.2)$ eggs/female/month at BEL, and 404 ( \pm 82.2$)$ eggs/ female/month at RUC, all at $25^{\circ} \mathrm{C}$, and $284( \pm 59.2)$ eggs/ female/month at $22^{\circ} \mathrm{C}$ ( $\mathrm{ABC}$ data).

There have been conflicting observations on seasonality of egg production patterns in cultured M. cornuarietis reared under constant laboratory conditions. The University of Sussex (D. Thomas, personal communication) has observed no annual cycling of sexual performance in $M$. cornuarietis cultured under constant light and temperature (i.e. $12 \mathrm{~L}: 12 \mathrm{D}, \mathrm{ca} .25^{\circ} \mathrm{C}$ ). A slight depression of sexual activity during the winter months, but no sexual repose during spring and summer, was observed in $M$. cornuarietis cultures of the Danish Bilharziasis Laboratory (H. Madsen, personal communication). In contrast, Oehlmann et al. (2000) and Oehlmann et al. (2006a) reported that reproduction of $M$. cornuarietis cultures maintained under constant temperatures of 20,22 , and $27^{\circ} \mathrm{C}$ is seasonally controlled with peak copulation and spawning activity occurring in November, December, and January, the other months of the year being the sexual repose phase (with reduced egg-laying activity). In the present study, snails in all laboratories decreased their egg production somewhat during the 7 month trials. Although this could potentially have been attributed to a seasonal cycle, the full year trial at RUC clearly demonstrated that there is no seasonality in reproduction of these snails when maintained under constant laboratory conditions at $25^{\circ} \mathrm{C}$. If data are presented on the basis of calendar month (Figure 2b), rather than month from start of the trial (Figure 2a), seasonality could incorrectly be attributed. Even if such seasonality were (incorrectly) concluded, it would appear that the peak reproductive period was in July-August, which is very different to the observations of Oehlmann and colleagues. However, rather than seasonality, we believe that the observed change in reproductive rate is an effect of snail age, since snails did not show any signs of returning to starting egg production rates toward the end of the full-year trial.

None of the studies by Oehlmann and colleagues controlled for differences in snail age within or among treatments. However, such substantial temporal fluctuations in reproductive output as observed by these au- thors could be attributed to a variety of factors, other than season, which are known to influence reproduction in this species. Photoperiod, temperature, food quality and quantity, various water quality parameters, and snail density have all previously been reported to affect performance of M. cornuarietis (Demian and Yousif, 1973; Hofkin et al., 1991; Robins, 1971; Selck et al., 2006). It has been shown that densities above around 1 snail/L can have a negative influence on adult reproductive output and juvenile growth (Aufderheide et al., 2006). In the trials conducted at RUC under semi-static conditions (with a similar filter system as that used by Oehlmann et al., 2000, 2006a) particular care had to be taken to control ammonia below toxic levels even at densities $<1$ snail/L. In the experiments reported by Oehlmann et al. (2000, 2006a), initial snail densities were much higher than 1 snail/L (up to 3.5 snails/L) and they declined (because snails were harvested for analysis) during the course of the studies. This could potentially have led to increases in reproductive output over time, and in addition to the fact that sex ratio was not controlled in the studies, could have led to differences among aquaria that had nothing to do with chemical treatment.

Egg hatchability was above $80 \%$ in all laboratories and replicates and in both trials, and averaged about $90 \%$. It took eggs an average of 10.5 days to reach the first hatch and 12 days to reach $50 \%$ hatch. Though there were some differences among laboratories and trials in time to firstand $50 \%$ hatch, these differences were generally small (on the order of \pm 1 day). The poorer hatchability in the second BEL trial compared to the first occurred, despite the majority of individual egg masses being comparable between trials, was a result of a higher incidence of egg masses with very poor hatchability.

There were some differences in juvenile growth rates among laboratories with snails reaching a significantly larger shell diameter at $60 \mathrm{dph}$ at $\mathrm{ABC}$ laboratory compared to BEL and RUC. It may be that juvenile snails are particularly sensitive to small environmental heterogeneities that differed among laboratories. Nevertheless, juveniles in all laboratories reached the size of morphological maturity (ca. $20 \mathrm{~mm}$ shell diameter) by an age of 3 months as expected from previous studies (Selck et al., 2006).

The results from the trials at $\mathrm{ABC}$ comparing snail performance at 22 and $25^{\circ} \mathrm{C}$ showed that adult snails had lower reproductive outputs at the lower temperature (284 vs. 440 eggs/female/month, respectively) and that the variability among replicate aquaria was greater at the lower temperature (inter-replicate coefficients of variation were $21.0 \%$ at $22^{\circ} \mathrm{C}$ and $6.6 \%$ at $25^{\circ} \mathrm{C}$ ). This could have important implications for statistical power (i.e., for a given number of replicates per treatment, it would be more difficult to detect statistical differences among treatments at the lower temperature). Likewise percent hatchability of eggs was lower at $22^{\circ} \mathrm{C}$ compared to $25^{\circ} \mathrm{C}$, and it took snails about a week longer to hatch at the lower 
temperature. Snails also grew more slowly at the lower temperature and were about $7 \mathrm{~mm}$ smaller and $1.74 \mathrm{~g}$ lighter at an age of $60 \mathrm{dph}$. All of these life-history responses suggest that fitness of this species is reduced at the lower temperature. These observations are consistent with other controlled laboratory studies (Aufderheide et al., 2006; Selck et al., 2006) and reflect the natural field distribution of this species, which is mainly in (sub) tropical areas of the Caribbean, Central, and South America (WHO, 1982). Since both culture protocols and toxicity tests are generally designed to optimize organism performance and minimize background stress, we recommend that the higher temperature of $25^{\circ} \mathrm{C}$ should be preferred for both snail culture and toxicity testing. Previous studies at ABC (Aufderheide et al., 2006) found no declines in snail performance between 25 and $28^{\circ} \mathrm{C}$ (indeed both egg hatching and juvenile growth were faster at the higher temperature), suggesting that temperatures in this range would be acceptable for snail culture and testing.

There was no observable effect of the type of husbandry (flow-through vs. semi-static conditions) on adult fecundity, egg hatchability, or juvenile growth. The significant differences among laboratories observed in trial 2 of the egg hatchability trials (Table 1) were largely due to the differences between BEL and $\mathrm{ABC}$, i.e., the two laboratories using flow-through, and not to differences between ABC (flow-through) and RUC (semi-static). Similarly, differences in juvenile growth rate between laboratories using flow-through (ABC and $\mathrm{BEL}$ ) were of similar magnitude as those between $\mathrm{ABC}$ (flow-through) and RUC (semi-static) (Table 2), suggesting that the flow conditions used here had no effect on juvenile growth.

Thus the present results, and those presented in Part II of this series (Forbes et al., in press), are in marked contrast to previously published studies on the reproductive performance of $M$. cornuarietis (Oehlmann et al., 2000, 2006a; Schulte-Oehlmann et al., 2001). We recommend that future tests of effects of BPA on M. cornuarietis be conducted (1) with an appropriate design that controls for and allows quantification of intra- and inter-snail variability in test endpoints, (2) under environmental conditions that are favorable for snail reproduction, growth and development, and (3) that employ sufficient replication and appropriate statistical methods. These issues will be further addressed in Part II.

\section{Conclusion}

The results of this study highlight the importance of obtaining fundamental knowledge of husbandry requirements and baseline information on life-history traits of potential ecotoxicological test species prior to designing toxicity test protocols. Understanding of the levels and sources of endpoint variability is essential so that statistically robust and ecologically relevant toxicity tests can be conducted.
Acknowledgments - We are grateful to Gary Klecka (The Dow Chemical Company), Ellen Mihaich (Consultant to GE Advanced Materials), Charles Staples (Assessment Technologies, Inc.), Steven Hentges (American Plastics Council), and David Thomas (Consultant to PlasticsEurope) for helpful discussions and valuable comments on the manuscript. Financial support was provided by the Bisphenol A Global Industry Group.

Funding source - This work was funded by the Bisphenol A Global Industry Group. All experiments were conducted in accordance with national and institutional guidelines for the protection of animal welfare.

\section{References}

Aufderheide, J., Warbritton, R., Pounds, N., File-Emperador, S., Staples, C., Caspers, N., Forbes, V., 2006. The effects of husbandry parameters on the life-history traits of Marisa cornuarietis: effects of temperature, photoperiod and population density. Invert. Biol. 125, 9-20.

Cowie, R.H., 2002. Apple snails as agricultural pests: their biology, impacts, and management. In: Barker, G.M. (Ed.), Molluscs as Crop Pests. CABI Publishing, Wallingford, pp. 145-192.

Demian, E.S., Yousif, F., 1973. Embryonic development and organogenesis in the snail Marisa cornuarietis (Mesogastropoda: ampullariidae). 1. General outlines of development. Malacologia 12, 123-150.

Dietrich, D.R., O'Brien, E., Hoffmann, S., Balaguer, P., Nicolas, J.-C., Seinen, W., Depledge, M., 2006. Effects of BPA in snails. Environ. Health Persp. 114, A340-A341.

EC, 2003. European Union Risk Assessment Report: Bisphenol A-3rd Priority List, volume 37. Institute for Health and Consumer Protection, Joint Research Centre, Ispra, Italy. Available at: <http://ecb.jrc.it/DOCUMENTS/Existingchemicals/RISK_ASSESSMENT/REPORT/bisphenolareport325.pdf>.

Forbes, V.E., Aufderheide, J., Warbritton, R., van der Hoeven, N., Caspers, N., in press. Does bisphenol A induce superfeminization in Marisa cornuarietis? Part II: toxicity test results and requirements for statistical power analyses. Ecotoxicol. Environ. Saf., in press, doi:10.1016/j. ecoenv.2006.09.001.

Goodman, J.F., McConnell, E.E., Sipes, I.G., Witorsch, R.J., Slayton, T.M., Yu, C.J., Lewis, A.S., Rhomberg, L.R., 2006. An updated weight of the evidence evaluation of reproductive and developmental effects of low doses of bisphenol A. Crit. Rev. Toxicol. 36, 387-457.

Haridi, A.A.M., El Safi, S.H., Jobin, W.R., 1985. Survival, growth and reproduction of the imported ampullarid snail M. cornuarietis in central Sudan. J. Trop. Med. Hygiene 88, 135-144.

Hofkin, B.V., Stryker, G.A., Koech, D.K., Loker, E.S., 1991. Consumption of Biomphalaria glabrata egg masses and juveniles by the ampullariid snails, Pila ovata, Lanistes carinatus and Marisa cornuarietis. Acta Tropica 49, 37-44. 
Oehlmann, J., Schulte-Oehlmann, U., Tillmann, M., Markert, B., 2000. Effects of endocrine disruptors on prosobranch snails (Mollusca: Gastropoda) in the laboratory. Part I: Bisphenol A and Octylphenol as xeno-estrogens. Ecotoxicology 9, 383-397.

Oehlmann, J., Schulte-Oehlmann, U., Bachmann, J., Oetken, M., Lutz, I., Kloas, W., Ternes, T.A., 2006a. Bisphenol A induces superfeminization in the ramshorn snail Marisa cornuarietis (Gastropoda: Proso-branchia) at environmentally relevant concentrations. Environ. Health. Persp. 114 (Suppl. 1), 127-133.

Oehlmann, J., Schulte-Oehlmann, U., Bachmann, J., Oetken, M., Lutz, I., Kloas, W., Ternes, T.A., 2006b. Effects of BPA in snails: Oehlmann et al. respond. Environ. Health Persp. 114, A341-A342.

Robins, C.H., 1971. Ecology of the introduced snail, Marisa cornuarietis (Ampullariidae) in Dade County, Florida. Biologist 53 (3), 136-152.

Schulte-Oehlmann, U., Tillmann, M., Casey, D., Duft, M., Markert, B., Oehlmann, J., 2001. Ostrogenartige Wirkungen von Bisphenol A auf Vorderkiemenschnecken (Mollusca: Gastropoda: Prosobranchia). UWSF-Z Umweltchem Okotox 13, 319-333.
Selck, H., Aufderheide, J., Pounds, N., Staples, C., Caspers, N., Forbes, V., 2006. The effects of food type, feeding frequency, and temperature on juvenile survival and growth of Marisa cornuarietis (Mollusca: Gastropoda). Invert. Biol. 125, 106-116.

Sokal, R.R., Rohlf, F.J., 1995. Biometry, $3^{\text {rd }}$ ed. W.H. Freeman and Company, New York.

Staples, C.A., Dorn, P.B., Klecka, G.M., O’Block, S.T., Harris, L.R., 1998. A review of the environmental fate, effects and exposures of bisphenol A. Chemosphere 36 (10), 2,149-2,173.

Staples, C.A., Woodburn, K., Caspers, N., Hall, A.T., Klecka, G., 2002. A weight of evidence approach to the aquatic hazard assessment of bisphenol A. Hum. Ecol. Risk Assess. 8, 1,083-1,105.

Vom Saal, F.S., Hughes, C., 2005. An extensive new literature concerning low-dose effects of bisphenol A shows the need for a new risk assessment. Environ. Health Persp. 113, 926-933.

WHO, 1982. Data Sheet on the Biological Control Agent Marisa cornuarietis (Linn.). Information document produced by the WHO Division of Vector Biology and Control, 11p. 